\title{
Revitalizing Broken Dreams: First Year Female Student Nurses' Perceptions Regarding Their Decision to Join Nursing as a Career
}

\author{
Pir Bux Jokhio ${ }^{1 *}$, Musrat Fatima², Husan Bano Channer², Ghulam Abbas Panhwar ${ }^{3}$ and Abdul Rahim Mangrio ${ }^{4}$ \\ ${ }^{1}$ Begum Bilqees Sultana Institute of Nursing, Peoples University of Medical and Health Sciences for Women, Nawabshah, Pakistan \\ ${ }^{2}$ Peoples School of Nursing, Liaquat University of Medical and Health Sciences, Jamshoro, Pakistan \\ ${ }^{3}$ Benazir College of Nursing, Shaheed Muhtarama Benazir Bhutto Medical University, Larkana, Pakistan \\ ${ }^{4}$ School of Nursing, Peoples Medical College and Hospital, Nawabshah, Pakistan
}

\begin{abstract}
Background: Nursing is a dynamic profession. On the other hand, due to its poor social image, it is not regarded as a first career choice. Nurses' poor social image converts into a big challenge as the country is facing chronic nurses' shortage and retention issues. Both problems warrant devising policies to increase students' enrollment in nursing programs. Therefore, it is very necessary to explore nursing students' perceptions regarding their decision to choose nursing as a career.

Methodology: A qualitative descriptive study was employed which included a convenience sampling and a focus group discussion method to collect the data. Data were analyzed through thematic content analysis procedure. Two group discussions were arranged with 08 participants in each group. All the participants (16) were freshly enrolled in the first year (04-year) Bachelors' of Science in Nursing (session: 2018-19) at a Nursing Institute located in a female Medical University of Sindh Province.

Results: One main theme 'nursing as an opportunity to fulfill broken dreams' and four supporting themes as 'broken dreams; nursing as a way to continue your education; feeling as a nursing student and nursing as my destiny' were unearthed.

Conclusion: Student nurses are demotivated because their first dream remained unfulfilled. It is their confidence in themselves and curiosity to continue their education (that they stood up and decided to join nursing) to revitalize their broken dreams. A big opportunity falls on the shoulders of the Institute specially and teaching faculty, in general, to continuously support student nurses as they reenergize themselves to grow as professional and ethical nurse practitioners in the coming days.
\end{abstract}

Keywords: Nursing education, decision to enroll in a nursing program, nursing as a career, nursing as a prospect.

\section{INTRODUCTION}

Candidates for higher education pick nursing as a career although they might know its low professional status in the society [1]. Realistically speaking, some reasons influence an individual's decision to choose and join nursing as a career such as to secure a job easily'. Secondly, the majority of the individuals had preferences for and picked nursing when they failed to meet their primary objectives successfully [2]. Most of the candidates joined nursing because admissions in nursing were easy as compared to medicine. On the other hand, demotivating factors such as a low paid job involving excessive workload and an unpleasant work environment were considered as main obstacles to choose nursing as a career [3]. Nevertheless, nursing is an area with maximum job opportunities and leading to improve financial standings [4]. Nursing images must be improved as persons desiring to join this profession may not feel insecure after their decision to join nursing [5]. It will improve enrollment in the nursing program to deal with the critical nursing shortage and retention issues [1].

\footnotetext{
*Corresponding Author: Pir Bux Jokhio, Assistant Professor Nursing, Begum Bilqees Sultana Institute of Nursing, Peoples University of Medical and Health Sciences for Women, Nawabshah, Pakistan; Email: pjokhyo@pumhs.edu.pk Received: September 26, 2019; Revised: November 11, 2019; Accepted: December 09, 2019 DOI: https://doi.org/10.37184/lnjpc.2707-3521.1.1
}

The phenomenon of career choice is changing from traditional meaning and understanding of nursing as a noble, altruistic, caring and compassionate profession towards a profession about social standing such as the desire of autonomy, respect, and quality of life, job security, good pay, and social acceptance [6]. The poor public image of nursing as a career in the society detracts individual to join it as a career. Secondly, the low status of the profession results in the loss of self-confidence among people who had joined nursing as a career [7].

The professional nursing image from the Pakistani perspective is documented as low. Lack of public acknowledgment and appreciation for profession, poor working conditions, lack of respect from doctors, and limited autonomy for role performances according to jobrelated specifications could be the reasons for its low image [8]. Moreover, it was also revealed that students' perceptions of nursing as a profession have changed from negative to positive. It was acknowledged that nursing was respectable and equal to other professions. This was an encouraging stimulus [9]. Keeping in mind these students' changed perceptions, the new research is also warranted in other parts of the country to know the current status of students' perceptions vis-à-vis nursing as a career. Little is known about the current students' perceptions of nursing as a career. The aim of the study was 'to explore nursing students' perception concerning their decision to enroll in 04-years Bachelors' of Science 
in Nursing (BSN-Generic) program and choose nursing as a career". The objectives of the study were: 1) to describe nursing students' views about joining nursing as a career and 2) to ascertain the factors that motivated them to enroll in BSN-Generic program.

\section{METHODOLOGY}

A qualitative approach was used to explore nursing students' perceptions regarding their decisions to pick nursing as a career. A semi-structured (three openended items) questionnaire was used to collect the data. The research questions were: 1 ) why did you decide to take admission in the undergraduate BS Nursing degree program and choose nursing as a career; 2 ) how do you feel now as a nursing student after securing admission here; and 3) tell me the reason(s), you will leave nursing studies if there is an opportunity before you to be enrolled and study in a different undergraduate degree program other than nursing. The method for data collection was the focus group discussion. Two focus group discussions (each group containing eight participants) were arranged. The population for the study was newly enrolled 1 st year BS Nursing degree program (04 years) session 201819. The study was conducted in the Peoples University of Medical and Health Sciences for Women, located at District Shaheed Benazir Abad, Sindh.

All the students were informed about the aim of the study and written informed consent was taken. The first author of the study moderated the first session and second author of the study took notes of the session. The third author of the study moderated the $2^{\text {nd }}$ session and fourth author took the notes. All authors remained present during both the group focus discussions. Each session lasted for 50 minutes. Before conducting the study, an approval was granted from the Ethical Committee,
Peoples University of Medical and Health Sciences for Women, Nawabshah, Shaheed Benazirabad through letter \# 977 dated 19/05/2019. Data were collected during the month of June 2019.

Data were analyzed through thematic content analysis method. All the notes were carefully read several times by all authors to get the basic idea of the contents. We kept questions before and redlined and/or crossed sentences/words from main text transcripts. Each point of text transcript was indicated as a code. For example the text transcript; 'my parents always wished for me that I become a doctor' was coded as 'parents' (and/ or relatives') wishes'. Different codes were grouped to create a sub-theme. Four sub-themes emerged from raw data and a main theme 'nursing as an opportunity to fulfill broken dreams' developed (See Table 1). All authors sat for three meetings and finalized the themes with extensive discussion. This is an inductive method of thematic data analysis proposed by Ravindran [10].

\section{RESULTS}

This was a descriptive qualitative study to explore the contemplations of first-year nursing students' perceptions regarding their decision to choose nursing as a career. All the research participants were females and age ranged between 18-21 years. It was revealed that the main factor that motivated participants to make a decision to be enrolled in the nursing program and choose nursing as a career was 'nursing as an opportunity to fulfill one's broken dreams'. Research participants expressed that they saw 'nursing admission' as an opportunity and blessing to continue their education after they became disheartened due to their inability to secure their admission in the Bachelors of Medicine and Bachelors of Surgery (MBBS) program.

Table. 1: Main theme: Nursing as an opportunity to fulfill one's broken dreams.

\begin{tabular}{l|l|l|l}
\hline $\begin{array}{l}\text { S. } \\
\text { No }\end{array}$ & \multicolumn{1}{|c|}{ Sub-themes } & \multicolumn{1}{c}{ Code } & \multicolumn{1}{c}{ Text Transcripts } \\
\hline 1 & Broken dreams & $\begin{array}{l}\text { Parents' (and/or relatives) wishes } \\
\text { Inability to pass MBBS entry test } \\
\text { To be a doctor is valued } \\
\text { To be a nurse is less appreciated }\end{array}$ & $\begin{array}{l}\text { My parents always wished for me that I become a doctor. } \\
\text { Although appeared in the entry test, didn't clear for MBBS admission. } \\
\text { Doctors are more valued and respected in society. } \\
\text { Nurses are not appreciated and regarded good persons in society. }\end{array}$ \\
\hline 2 & $\begin{array}{l}\text { An opportunity to continue } \\
\text { education }\end{array}$ & $\begin{array}{l}\text { Family Support } \\
\text { Own interest } \\
\text { To be an example } \\
\text { My Destiny } \\
\text { Job opportunity } \\
\text { Nursing same as MBBS }\end{array}$ & $\begin{array}{l}\text { My parents advised me to join nursing as the second option. } \\
\text { I wanted to continue my education as I was not selected for MBBS } \\
\text { in first place. } \\
\text { I want to be an example for those girls who discontinued their } \\
\text { education after their inability to secure admission in MBBS. } \\
\text { Something written in your destiny might be accepted by you as it is a } \\
\text { blessing from Allah after you were disheartened. } \\
\text { There are many job opportunities as a nurse here and abroad. } \\
\text { Nursing is same as MBBS. }\end{array}$ \\
\hline 3 & To be a nursing student & $\begin{array}{l}\text { Excited, happy, and/or more } \\
\text { satisfied } \\
\text { Right place } \\
\text { Good nurse } \\
\text { Work hard }\end{array}$ & $\begin{array}{l}\text { Now, I am happy, excited, more than satisfied that I decided to join } \\
\text { the nursing. } \\
\text { This is the right place to learn and serve the people. } \\
\text { I will be seeing in me a good future nurse. } \\
\text { I will work hard to achieve good grades and be a gold medalist. }\end{array}$ \\
\hline 4 & Now, Nursing is my destiny & $\begin{array}{l}\text { Time to change the attitude } \\
\text { Good learning Environment } \\
\text { Future ambitions } \\
\text { A step forward towards success }\end{array}$ & $\begin{array}{l}\text { No profession is bad. It is time to change the attitude of society } \\
\text { towards nursing. } \\
\text { Here, we have a good learning environment, with the help of parents } \\
\text { and teachers, we will work hard to achieve our objectives. } \\
\text { I am proud and confident that I have taken a step forward towards a } \\
\text { success. }\end{array}$ \\
\hline
\end{tabular}




\section{a. Broken Dreams:}

The first sub-theme 'broken dreams' was constructed as an inability to secure admission in the MBBS program. The majority of the participants revealed that their parents (father and mother) and relatives (such as elder brother, elder sister, aunty and uncle) had wished and prayed for them to be a doctor (MBBS). Moreover, their interest was in studying MBBS. Therefore, they had made the mind to appear in the MBBS entry test. For that, they worked hard. Unfortunately, they failed to qualify for MBBS. It was a deplorable movement and made them deterred and dismayed. The main reason behind their wishes to be a doctor was that the doctors are valued and appreciated in the society. In contrast, the nursing profession has an opposite image as that of less valued and appreciated. The participants stressed that their parents' and relatives' priority was MBBS; therefore, they were reluctant to allow their children to join nursing as a first-choice career.

b. Nursing as an Opportunity to Continue Your Education:

The second sub-theme was recognized as 'nursing as an opportunity to continue your education'. After failing to secure an admission in the MBBS program, the participants expressed that they were highly disheartened. After sometimes, they read news about nursing program admission in the newspapers and decided to join it. There were several reasons behind this deviation. Some of the students decided out of their interest and yearning to continue their education. They felt that nursing is like MBBS and is a part of the larger health care system of society. They found that they can revitalize their broken dreams of becoming an MBBS doctor by joining nursing. They can wear white overcoat (apron) and work along with other health care professionals. In this way, they can also serve the ailing community. Secondly, they wanted to set an example for the girls who opted to discontinue their education and preferred to stay at home. Research participants explored that their new decision was well received by their parents. Their parents also agreed that nursing was better if they didn't thrive in their first choice. Nevertheless, some of the research participants were resisted in their new decision by their parents but the research participants became successful in convincing them (parents) to allow them for joining nursing and they disclosed their parents' permission on the notion that parents should be informed that nursing is a dynamic and growing field and there are many chances of job opportunities in Pakistan and abroad.

\section{c. Feelings as Nursing Students:}

The third sub-theme was extracted as 'feelings as a nursing student'. Students expressed their feelings being nursing students as happy, excited, more than satisfactory, enjoying, convinced and satisfied. They thought that they were in the right place and did not need to move on. For some, it was termed as an auspicious opportunity bestowed upon them by almighty Allah, so they should be thankful to Allah. They expressed that they will work hard and try to pass their examinations with flying colors. One student anticipated that solid work is an indicator of accomplishment and she will endure it to be a Gold medalist. Another student said that she was moderately bumpy initially and had decided to withdraw from the program. Then, she began to adjust herself here because leaving or withdrawing could be more dangerous in the future. Therefore, she was trying to face the situation and trying to concentrate on her studies.

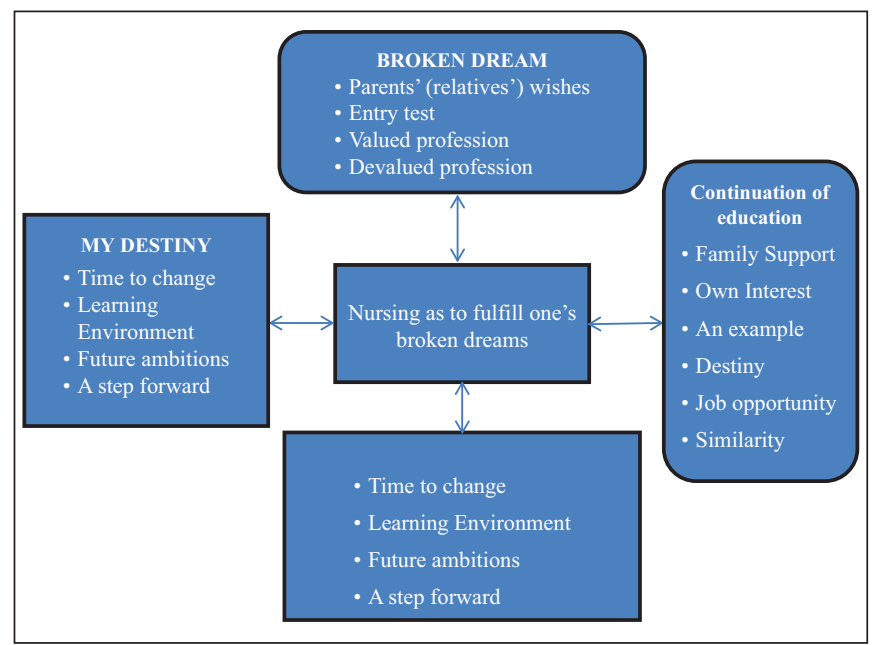

Fig. (1): Revitalizing broken dream model in nursing education.

\section{d. Now, Nursing is my Destiny:}

As a last sub-theme of the study, 'now, nursing is my destiny' was revealed. The majority of the research participants maintained that they will not change the nursing profession. They had confidence in themselves and were in the right place. They didn't need to go to any other field. They assumed that people are changing their perception towards nursing and it is the right time to make efforts to alter society's attitude towards the nursing profession. They postulated that parents will also allow their children to join nursing as a career without any confrontation if the image of nursing improves in the society. They had found a good learning environment in nursing with the support of faculties. They also divulged that they had no alternative to discontinue their education in this competitive world. Therefore, it is better to find alternatives, if you fail to realize your first career choice. Lastly, they conjectured that all is written in your destiny and one of the finest options is to admit it so accept it with open arms. They concluded that they have taken the right step, a step forward towards success and with the blessings of almighty Allah and prays of their parents, they will procure their destination unmitigated. On the basis of inductive process of data analysis, we have unanimously suggested 'revitalizing broken dreams model for nursing education' (see Fig. 1).

\section{DISCUSSION}

To the authors' best knowledge, this is the first kind of study in the Pakistani context that is conceded 
to explore nursing students' perceptions regarding their decision to join nursing as a career. The study is conducted qualitatively, therefore, the generalizability of the results cannot be claimed. Nevertheless, the study has discovered valuable insights on the subject. The main theme extracted as nursing education as a way to fulfill broken dreams is a very different and unique idea discovered in this current study. In a study [1] conducted in Poland, it was expressed that one of the reasons to join nursing career was their inability to be enrolled in another course. In that study [1], the nature of another course remained unearthed. In our study, it was discerned that students capitalized this because they were not able to annex admission in MBBS. To be a doctor after completing MBBS was not only their recourse but participants' parents had also craved for their children to be doctors in the future.

The first sub-theme broken dreams shed light on the participants' wishes constructed on their interest and their parents' desire and prayers for their children to be engraved in the MBBS program. There were two main impetuses to join the MBBS program as a first choice. One is that the doctors (MBBS) are appreciated and regarded as valued parts and parcels and as compared to the doctors, nurses attain much less social importance. The findings of the study are seconded on a relatively small scale with a study conducted in Japan [9]. That study [9] unveiled that some of the participants lacked the deep-down curiosity to be registered in a nursing program and tracked that route because they had initially planned to choose another career (such as researcher). As they failed to make a way towards their fundamental purpose, nursing surfaced before them as a beginning step in attainment and grasping their down to drain resolution. In another longitudinal study [11] conducted in Australia, the participants evoked that their decision apropos to admission in a nursing program incorporated both personal as well as career ambitions. The main personal ambitions were caring and helping others, seeing self as a nurse and making a difference. On the other hand, career ambitions included a safe, secure and stable job, an area of diversity to validate your capabilities, job opportunities abroad, able to travel, extending career choices, and stepping stone to other career choices [11].

The second sub-theme nursing as an opportunity to continue your education is reckoned as selecting nursing as a career after failing to secure a slot in the MBBS program. This sub-theme is supported as own interest to continue education, with the support of the parents and relatives. Participants were influenced and motivated on the notion that their children shouldn't discontinue their educational journey and become an example for those girls who decide to stay at home rather than pursuing an education in an alternative field. Parents supported their children for this change in taking decision. Some of the parents were convinced by their children on the notion that nursing is also like an MBBS doctor. There are multiple job opportunities in the country and abroad after completing a nursing degree. The first part of the finding of the study that illuminates that research participants decided to join nursing and be an example for those girls who remained at home and refused to continue their education is a unique revelation in this study. On the other hand, the findings of more job opportunity in the country and abroad is supported by multiple studies. The study [2] conducted in Istanbul, Turkey revealed that the reasons behind students' decision to study nursing were taken on the notion that a participant's relative was working as a nurse already, having positive feelings towards the profession, and job security (although not their basic choice because of their first choice for a career as some other field other than nursing). Participants of the study [2] expressed that they were uncomfortable with joining nursing as a career only because society didn't consider nursing as a valuable profession.

The third sub-theme of Feeling as a nurse as excited, happy, more than satisfactory, will work hard to achieve gold medals are well supported in other studies. The findings are closely supported through a qualitative study [12] conducted in Turkey. The study results determined that students are very hopeful that they will be molded as persons who promote interaction with patients through professional knowledge and values gained during classes and in their clinical learning. As a therapeutic relationship between a nurse and a patient is based on essential and productive communication, therefore, students' professional knowledge and value development will ensure the artistic aspects of nursing. In another study [13] conducted in Iran, the results showed that nurse students labeled clinical teaching and/or clinical teachers as promoters of evidencebased-nursing through building a trusting relationship between a student and a teacher and enhancing their confidence. Participants of that study considered that the aforementioned strategy will make students hungry to learn [13].

The last sub-theme of nursing as my destiny revolves around the categories of time to change attitudes towards nursing profession, a good learning environment, future ambitions and a step forward. The results of the study are congruent with a study [14] conducted in Iran. According to the study [14], nursing education could take advantage of informal learning to promote students' maturity, nontechnical skills, and emotional and social development to produce more competent nurses. Personal maturity and emotional growth are achieved through selfawareness, self-discovery, accelerated mental maturity, appreciation, kindness, and altruism. In this way, they may recover from their broken dreams by revitalizing their lost energies. Through social development, they will be exposed to and accept diversity, improve interpersonal and humanistic interactions and will be satisfied with their new assignment as a nurse. In this way, nurse 
retention can be improved. Lastly, developing a value system and ethical and professional commitments will help them in developing a sense of connection with almighty Allah, and thereby the following consciousness, they will respect patients' rights and dignity. In this way, they can discharge their proper responsibilities ethically and professionally to ensure patients' safety. That will be actual revitalizing their broken dreams [14].

Therefore, we suggest a new nursing model named 'revitalizing broken dreams model for nursing education' (see Fig. 1) in Pakistani context. This is a first step in this direction. It is strongly hoped that model will help nursing institutions and policy makers to understand the emotional and psychological impact of candidates' decisions as soon as they join nursing as a career.

\section{CONCLUSION}

Nursing is a dynamic and ever-changing field. There are many job opportunities in and around the corner. The main reason that students are reluctant to join the nursing degree program and nursing as a career is their priority to join the medical field. It is time to realize the students that each one may not be successful to be a future doctor. It is not bad to try for it. Therefore, they must not be dismayed if they fail to achieve their first goal. They must be open to other chances and nursing is one of them. On the other hand, institutions and policymakers of the nursing field must support their students in every step. There is a need to work for improvement in the current image of nursing among masses at the grass root level. In this way, the parents will be mobilized to allow their children to choose nursing as their first choice. The model developed through this study will help all the stakeholders to revise their policies if they plan to improve the nursing shortage issue in the country. The model is in infancy. More quantitative research is required to enhance its reliability and validity.

\section{CONFLICT OF INTEREST}

There is no conflict of interest involved in this study. This study has been conducted as a professional activity and for a desire to develop a nursing research culture among nurse professionals.

\section{ACKNOWLEDGEMENTS}

All the authors have contributed significantly from the conception of the research problem to the end of the final write up. The first and second authors of the study initially conceptualized the study. Then, with the help of the third author, we concluded the literature review, proposal writing and submitting it into the ethical review committee. All the authors contributed to data collection. The first three authors took the responsibility of analyzing the data. Finally, all the authors provided their valuable input in finalizing this write up. The first and second authors wrote the final report. The first author took responsibility of the corresponding author. All the authors are extremely pleased with the research participants (students of the first year) for their time for this study.

\section{SOURCE OF FUNDING}

This study doesn't approach for any type of funding as this is a focus group discussion method studied at a university institute.

\section{REFERENCES}

1. Marcinowicz L, Owlasiuk A, Slusarska B, et al. Choice and perception of the nursing profession from the perspective of Polish nursing students: a focus group study. BMC Med Educ 2016; 16 : 243-50.

2. Elibol E, Seren AK. Reasons nursing students choose the nursing profession and their nursing image perceptions: a survey study. Nurs Pract Today 2017; 4: 67-78.

3. Tawash E, Cowman S. Bahraini nursing students' attitudes: from student to nurse-A longitudinal research study. J Nurs Educ Pract 2015; 5: 79-87.

4. Al-Jarrah IA. Associate nursing students' perceptions toward nursing profession in Jordan. Euro Sci J 2013; 9: 147-66.

5. While A, Blackman C. Reflections on nursing as a career choice. J Nurs Manag 1998; 6: 231-7.

6. Price SL. The experience of choosing nursing as a career: narratives from millennial nurses. Ph.D. Thesis, University of Toronto: Toronto, 2011. Retrieved from https://tspace.library. utoronto.ca/bitstream/1807/31905/3/Price_Sheri_L_201111_PhD thesis.pdf 10th June 2019

7. Çoban GJ, Şirin M, Kavuran E. Nurses' views on their profession and job satisfaction: a qualitative study. Balikesir Heal Sci J 2015; 4: 79-84.

8. Gul R. The image of nursing from nurses' and non-nurses' perspective in Pakistan. Silent Voice 2008; 1: 4-17.

9. Kawakami C, Imafuku R, Tsunekawa K, et al. Reasons and decision-making processes for applying to nursing school among nurses showing delayed professional development. J Nurs Educ Pract 2018; 9: 21-6.

10. Ravindran V. Data analysis in qualitative research. Indian J Cont Nsg Edn 2019; 20: 40-5

11. Wilkes L, Cowin L, Johnson M. The reasons students choose to undertake a nursing degree. Collegian 2015; 22: 259-65.

12. Duran ET, Çetinkaya-Uslusoy E. Opinions of nursing students on the art of nursing: a qualitative study. Int J Care Sci 2015; 8: 30816.

13. Moonaghi HK, Mirhaghi A, Oladi S, et al. A journey across an unwelcoming field: A qualitative study exploring the factors influencing nursing students' clinical education. H Sci J 2015; 9: 1-6.

14. Seylani K, Negarandeh R, Mohammadi E. Iranian undergraduate nursing student perceptions of informal learning: A qualitative research. Iran J Nurs Midwifery Res 2012; 17: 493-500. 